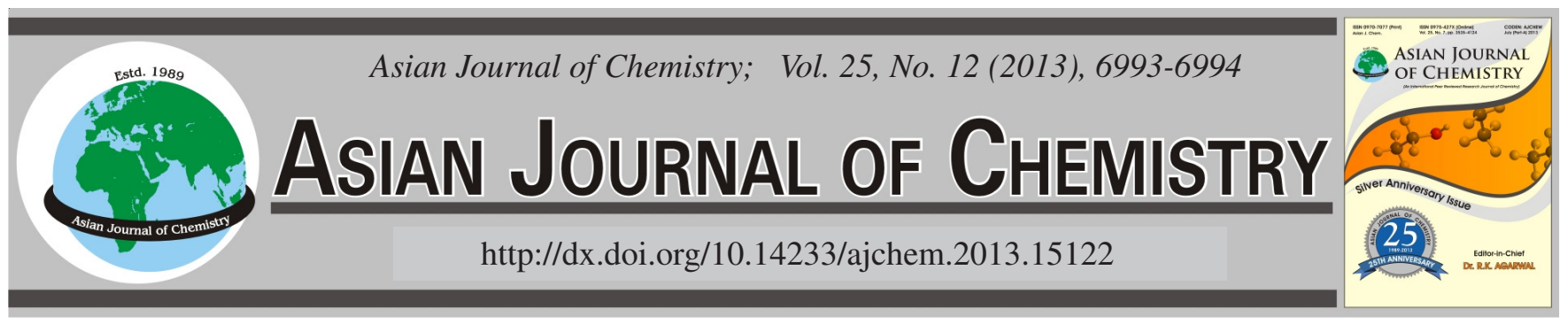

NOTE

\title{
Determination of Trace Metals in Engine oil by Direct Sample Introduction Inductively Coupled Plasma Mass Spectrometry
}

\author{
Luo Chuan ${ }^{*}$, Beilei Wu and Ying Zhang
}

Ningbo Entry-Exit Inspection and Quarantine Bureau, Mayuan Road 9\#, Ningbo 315012, P.R. China

*Corresponding author: Fax: +86 574 87116346; E-mail: lc801113@ gmail.com

(Received: 10 January 2013;

Accepted: 10 June 2013)

AJC-13621

\begin{abstract}
A rapid method was developed for the determination of the vanadium, manganese, nickel, copper, silver, cadmium, tin, barium and lead in engine oil by inductively coupled plasma mass spectrometry (ICP-MS). Direct sample introduction was performed with a special organic sample kit after dilution of the high viscosity engine oil with a suitable organic solvent. The sample up-take rate was optimized be to $50-100 \mu \mathrm{L} / \mathrm{min}$ with a continuous dose of additional $\mathrm{O}_{2}(20 \%)$ in the aerosol gas to prevent the deposition of carbon on the sampler and the extinction of plasma by the high viscosity of engine oil. The detection limits were less than $3.18 \mathrm{ng} / \mathrm{g}$. The relative standard deviations were less than $4.9 \%$. The spiked recoveries were $90.1-101.7 \%$.
\end{abstract}

Key Words: Engine oil, ICP-MS, Direct sample introduction, Trace metal.

The metal element of $\mathrm{Ca}, \mathrm{Zn}$, Mo and $\mathrm{Al}$ was added to the engine oil in order to improve the performance of the engine oil. Trace metal may be introduced due to raw material or production processes, therefore, the analysis of the trace metal of engine oil can be giving some fingerprint spectra information.

The metals in engine oil are commonly analysis by inductively coupled plasma atomic emission spectrometry $(\mathrm{ICP}-\mathrm{OES})^{1-7}$ or atomic absorption spectrometry (AAS) $)^{8,9}$, but the ICP-AES and AAS can only determine the micro metal in the engine oil, they are hardly to analysis the trace metal in the engine oil. Not only ICP-MS able to detect the trace metal in the engine oil, but also it could be analysis faster than AAS. Therefore, we used ICP-MS to analyze the trace metal in the engine oil.

\begin{tabular}{cccc}
\multicolumn{4}{c}{ TABLE-1 } \\
& \multicolumn{4}{c}{ ICP-MS OPTIMIZATION PARAMETER } \\
& FOR DETERMIANTION METALS \\
\hline Parameter & Value & Parameter & Value \\
\hline RF Power & $1570 \mathrm{w}$ & $\begin{array}{c}\text { Spray chamber } \\
\text { temperature }\end{array}$ & $-2^{\circ} \mathrm{C}$ \\
Sample depth & $9 \mathrm{~mm}$ & $\begin{array}{c}\text { Assistant gas flow } \\
\text { Optional gas flow }\end{array}$ & $0.20 \mathrm{~L} / \mathrm{min}$ \\
Carrier gas flow & $0.29 \mathrm{~L} / \mathrm{min}$ & $19 \%$ \\
\hline
\end{tabular}

The common methods for the pre-treatment of the organic sample for detect the metal elements by ICP-MS were acid digestion method ${ }^{2}$, ashing method, microwave assisted acid digestion method ${ }^{10}$, solvent extraction and electro thermal vaporization $^{11}$. The method of direct sample introduction after solvent dilution was less pre-treatment steps and shorter analysis time. So, we chose the direct sample introduction after solvent dilution to analysis the trace metal in the engine oil.

\begin{tabular}{ccccc}
\multicolumn{5}{c}{ TABLE-2 } \\
\multicolumn{5}{c}{$\begin{array}{c}\text { LINEAR EQUATION AND DETECTION } \\
\text { LIMIT OF EACH ELEMENTS }\end{array}$} \\
\hline Element & Mass & Linear equation* & $\mathrm{r}$ & $\begin{array}{c}\text { Detection } \\
\text { limit }(\mathrm{ng} / \mathrm{g})\end{array}$ \\
\hline $\mathrm{V}$ & 51 & $\mathrm{Y}=2110.4 \mathrm{X}+829.8$ & 0.9997 & 2.37 \\
$\mathrm{Mn}$ & 55 & $\mathrm{Y}=3306.2 \mathrm{X}+259.3$ & 0.9982 & 0.94 \\
$\mathrm{Ni}$ & 58 & $\mathrm{Y}=1450.1 \mathrm{X}+7358.4$ & 0.9983 & 0.64 \\
$\mathrm{Cu}$ & 63 & $\mathrm{Y}=1309.7 \mathrm{X}+774.2$ & 0.9968 & 1.95 \\
$\mathrm{Ag}$ & 107 & $\mathrm{Y}=1363.5 \mathrm{X}+100$ & 0.9973 & 0.49 \\
$\mathrm{Cd}$ & 111 & $\mathrm{Y}=564.6 \mathrm{X}+3.7$ & 0.9977 & 0.34 \\
$\mathrm{Sn}$ & 118 & $\mathrm{Y}=1252.8 \mathrm{X}+103.7$ & 0.9996 & 1.08 \\
$\mathrm{Ba}$ & 138 & $\mathrm{Y}=2890.5 \mathrm{X}+44.5$ & 0.9973 & 3.18 \\
$\mathrm{~Pb}$ & 208 & $\mathrm{Y}=3136.9 \mathrm{X}+238.4$ & 0.9984 & 0.59 \\
\hline *X: Standard concentration; $\mathrm{Y}$ : signal intensity.
\end{tabular}

This method used solvent dilution engine oil sample, ICPMS direct sample introduction to determine of 9 kinds of trace metal. This method has a multi-element analysis, fast analysis speed, high sensitivity, precision and accurate advantages. 
TABLE-3

ACCURACY AND RECOVERY OF THE METHOD

\begin{tabular}{lccccccccc}
\hline \multicolumn{1}{c}{ Element } & $\mathrm{V}$ & $\mathrm{Mn}$ & $\mathrm{Ni}$ & $\mathrm{Cu}$ & $\mathrm{Ag}$ & $\mathrm{Cd}$ & $\mathrm{Sn}$ & $\mathrm{Ba}$ & $\mathrm{Pb}$ \\
\hline $\mathrm{RSD} \%,(\mathrm{n}=7)$ & 1.9 & 1.2 & 1.9 & 2.6 & 1.7 & 4.9 & 1.4 & 1.4 & 1.2 \\
Recovery \%,(n=5) (add 10 ng standard) & 97.7 & 101.7 & 96.7 & 100.4 & 91.2 & 90.1 & 92.4 & 97.6 & 99.3 \\
\hline
\end{tabular}

\begin{tabular}{|c|c|c|c|c|c|c|c|c|c|c|c|c|}
\hline \multicolumn{13}{|c|}{$\begin{array}{r}\text { TABLE-4 } \\
\text { METALS OF EN }\end{array}$} \\
\hline Trademark & Type & API & SAE & $\mathrm{V}$ & $\mathrm{Mn}$ & $\mathrm{Ni}$ & $\mathrm{Cu}$ & $\mathrm{Ag}$ & $\mathrm{Cd}$ & $\mathrm{Sn}$ & $\mathrm{Ba}$ & $\mathrm{Pb}$ \\
\hline Total & E7 Engine & CI-4/SL & $15 \mathrm{~W}-40$ & 73 & 611 & 81 & 0 & 2 & 23 & 0 & 116 & 45 \\
\hline BMW & Super power & $\mathrm{SM} / \mathrm{CF}$ & $5 W-40$ & 53 & 178 & 122 & 12 & 1 & 16 & 0 & 11 & 21 \\
\hline Shell & Helix Ultra & $\mathrm{SM} / \mathrm{CF}$ & $5 W-40$ & 46 & 112 & 122 & 2 & 2 & 15 & 1 & 16 & 20 \\
\hline Chrysler & Pennzoil platinum & $\mathrm{SN}$ & $5 \mathrm{~W}-20$ & 9 & 192 & 79 & 2 & 2 & 212 & 0 & 17 & 17 \\
\hline Kunlun & Tianrun & SG & $15 \mathrm{~W}-40$ & 28 & 247 & 109 & 92 & 73 & 73 & 20 & 245 & 106 \\
\hline Kunlun & Base Oil & HVI & 400 & 0 & 0 & 137 & 0 & 0 & 0 & 0 & 0 & 0 \\
\hline
\end{tabular}

All reagents were of analytical-reagent grade or higher. S-21 multi-element oil analysis standard (Conostan, USA), contains 21 elements, including the 9 kinds of elements as measured in this article. Concentrations were $50 \mathrm{mg} / \mathrm{kg}$. PremiSolv ICP solvent (Conostan, USA), S-21 oil analysis standard was diluted by PremiSolv ICP solvent, to get the configuration of 100, 50, 20 and $10 \mathrm{ng} / \mathrm{mL}$ standard working solution standbys. Agilent 7700x ICP-MS (Agilent Technologies Co. Ltd., USA). Replace the injection set and torch set to organic special set. Optional gas for the oxygen content of $20 \%$ argon-oxygen gas mixture, via a T-connection tube and into the torch of an organic solvent are mixed. The collision cell is unused because the measured elements received less interference.

Analytical procedures: weigh $1 \mathrm{~g}$ of engine oil sample, diluted by PremiSolv solvent, mixed using vortex mixer and constant volume to $10 \mathrm{~mL}$, direct sample introduction analysis by ICP-MS.

Select of dilution solvent: The common solvent used to dilution the oil substance according to the references ${ }^{1,4,12}$ were such as toluene, xylene, petroleum ether, ethanol, methyl tertbutyl ether, tetralin and aviation kerosene. Ethanol was difficult to dissolve majority heavy oil and engine oil because of its polarity. Petroleum ether can't be used for testing because the plasma appears bright in the center of the radiation zone after the sample diluted by the petroleum ether. Methyl tert-butyl ether also can't be used for testing because it will swell injection tube. Toluene and xylene try to avoid for use because of its easy lead to carbon deposition and it's highly toxic. Using tetralin may result to the accumulation of viscous precipitate in torch, therefore can't use tetralin. The sample viscosity is too large after diluted by the aviation kerosene dilution, resulting in each analysis process injection time is long and it is difficult to buy the pure aviation kerosene. The PremiSolv ICP solvent has good solubility, lower sample viscosity than aviation kerosene; it is satisfy the requirements for rapid analysis.
Linear equation and detection limit: Linear equation was created by the five different concentrations of solution; the detection limit of each element was calculated by the linear equation. Linear equation and detection limit of each element were shown in the Table- 2 .

Accuracy and recovery of the method: The accuracy of the developed method was tested with recovery experiments by spiking standard solution into the sample solution. The analytical results and recoveries are shown in Table-3. The relative standard deviations were 1.2-4.9\%. The spiked recoveries were 90.1-101.7\%.

Application to real samples: The method was applied to the determination of trace metal in difference trademark engine oil. The analytical results are shown in Table-4.

\section{ACKNOWLEDGEMENTS}

This work was financially supported by General Administration of Quality Supervision, Inspection and Quarantine of the People's Republic of China (Fund No.: 2009IK059).

\section{REFERENCES}

1. S.W. Zhong, W.H. Wang, X. Zhang and G.C. Zhu, Henan Sci., 22, 341 (2004).

2. Z.P. Huang and X.Z. Jin, Phys. Testing Chem. Anal. B: Chem. Anal., 41, 403 (2005).

3. Z.P. Huang Metallurgical Anal., 26, 2 (2006).

4. B.H. Sun, Modern Scient. Instrum., 6, 21 (1999).

5. S.P. Li, Lubricating Oil, 14, 41 (1999).

6. Standards of American Society for Testing and Materials, ASTM D5185-95.

7. Standards of American Society for Testing and Materials, ASTM D4951-96.

8. Q.L. Hou, S.R. Jiang and J.Y. Liu, Chin. J. Anal. Chem., 12, 198 (1984).

9. L.X. Liu and L.H. Sun, Petrochem. Technol., 29, 446 (2000).

10. P. Zhang, L. Fu and Y.J. Li, Metallurgical Anal., 29, 14 (2009).

11. T.D. Saint'Pierre, L.F. Dias, D. Pozebon, R.Q. Aucélio, A.J. Curtius and B. Welz, Spectrochim. Acta B, 57, 1991 (2002).

12. D.Y. Chen, M. Jing, X.R. Wang, M.H. Zhuang and Z.X. Ge, J. Instrum. Anal., 25, 101 (2006). 